\title{
Volumetric capnography for the evaluation of chronic airways diseases
}

This article was published in the following Dove Press journal:

International Journal of COPD

23 September 2014

Number of times this article has been viewed

\section{Liliani Veronez'}

Monica Corso Pereira ${ }^{2}$

Silvia Maria Doria da Silva ${ }^{2}$

Luisa Affi Barcaui ${ }^{2}$

Eduardo Mello De Capitani²

Marcos Mello Moreira ${ }^{2}$

IIma Aparecida Paschoal ${ }^{2}$

'Department of Physical Therapy,

University of Votuporanga

(Educational Foundation of

Votuporanga), Votuporanga,

${ }^{2}$ Department of Internal Medicine,

School of Medical Sciences, State

University of Campinas (UNICAMP),

Campinas, Sao Paulo, Brazil
Correspondence: Ilma Aparecida Paschoal

Tessália Vieira de Camargo, 126 Cidade

Universitária "Zeferino Vaz",

Campinas, São Paulo, Brazil,

CEP | 8083-970

Tel +55 I9 352। 7907

Email ilma@fcm.unicamp.br
Background: Obstructive lung diseases of different etiologies present with progressive peripheral airway involvement. The peripheral airways, known as the silent lung zone, are not adequately evaluated with conventional function tests. The principle of gas washout has been used to detect pulmonary ventilation inhomogeneity and to estimate the location of the underlying disease process. Volumetric capnography (VC) analyzes the pattern of $\mathrm{CO}_{2}$ elimination as a function of expired volume.

Objective: To measure normalized phase 3 slopes with VC in patients with non-cystic fibrosis bronchiectasis $(\mathrm{NCB})$ and in bronchitic patients with chronic obstructive pulmonary disease (COPD) in order to compare the slopes obtained for the groups.

Methods: NCB and severe COPD were enrolled sequentially from an outpatient clinic (Hospital of the State University of Campinas). A control group was established for the NCB group, paired by sex and age. All subjects performed spirometry, VC, and the 6-Minute Walk Test (6MWT). Two comparisons were made: NCB group versus its control group, and NCB group versus COPD group. The project was approved by the ethical committee of the institution. Statistical tests used were Wilcoxon or Student's $t$-test; $P<0.05$ was considered to be a statistically significant difference.

Results: Concerning the NCB group $(\mathrm{N}=20)$ versus the control group $(\mathrm{N}=20)$, significant differences were found in body mass index and in several functional variables (spirometric, $\mathrm{VC}$, $6 \mathrm{MWT}$ ) with worse results observed in the NCB group. In the comparison between the COPD group $(\mathrm{N}=20)$ versus the NCB group, although patients with COPD had worse spirometric and 6MWT values, the capnographic variables mean phase 2 slope (Slp2), mean phase 3 slope normalized by the mean expiratory volume, or mean phase 3 slope normalized by the end-tidal $\mathrm{CO}_{2}$ concentration were similar.

Conclusion: These findings may indicate that the gas elimination curves are not sensitive enough to monitor the severity of structural abnormalities. The role of normalized phase 3 slope may be worth exploring as a more sensitive index of small airway disease, even though it may not be equally sensitive in discriminating the severity of the alterations.

Keywords: volumetric capnography, spirometry, bronchiectasis, 6MWT, bronchitis

\section{Introduction}

The physiological principles of gas washout were first described more than 60 years ago and two different tests have been developed from them for clinical use: the single breath and the multiple gas washout techniques. It is said that these tests allow the detection of pulmonary ventilation inhomogeneity and also permit an estimate of the location of the underlying disease process. ${ }^{1}$

Inert gases, such as helium $(\mathrm{He})$, nitrogen $\left(\mathrm{N}_{2}\right)$, and sulfur hexafluoride $\left(\mathrm{SF}_{6}\right)$ have been used and the elimination curves that they produce during each expiration depict 
concentrations of the gas at different volumes until all the expiratory volume is expired. Irrespective of the gas used, all of the curves are the same and in each of them three phases can be identified: phase 1 , with very low concentrations of the gas, which corresponds to the elimination of the air that is in the anatomic dead space; phase 2 , generally a steep upward line, that represents the growing concentration of the gas that is eliminated from proximal alveolated air spaces; and phase 3 , that is almost a plateau line and represents the elimination of the gas from most of the alveoli in the lungs.

The peripheral airways have been termed the silent lung zone because the conventional lung function tests are unable to detect their involvement in disease processes.

The phase 3 slope is an important feature of gas washout curves and contains information about gas transport in the alveolated airways of the lung periphery. It varies in many pathological conditions of the lungs. ${ }^{2-7}$

Volumetric capnography is a technique that analyzes the pattern of $\mathrm{CO}_{2}$ elimination as a function of expired volume. It produces a curve, the capnogram, that represents the total amount of $\mathrm{CO}_{2}$ eliminated by the lungs during each breath. As we would expect, the capnogram has the same form as the other gas elimination curves, with the advantage of being obtained with a gas that is normally produced in the body and eliminated by the lungs., 8

The objective of this study was to measure normalized phase 3 slopes with volumetric capnography in patients with non-cystic fibrosis bronchiectasis (NCB) and in patients with chronic obstructive pulmonary disease (COPD) with the bronchitic phenotype (cough, hypersecretion, wheezing) in order to compare the slopes obtained for the two groups.

\section{Subjects and methods}

Our hospital (teaching hospital of the State University of Campinas) is a reference center for pulmonary diseases and we select for outpatient follow-up all the non-smoker patients with chronic sputum production and the smoker patients with the most severe manifestations of COPD (among other diseases not related to this study).

Twenty patients with NCB (NCB group) and 20 patients with COPD (Global Initiative for Chronic Obstructive Lung Disease [GOLD] grade 3 and 4 of airflow limitation $)^{10}$ with hypersecretion phenotype (chronic bronchitis [CB] group) were serially enrolled at the moment of their routine evaluation at our outpatient clinic. All patients who agreed to participate in the study were submitted to the pulmonary function tests (spirometry and volumetric capnography) and the 6-Minute Walk Test (6MWT) on the same day of their consultation.
A control group was established for the group of patients with bronchiectasis, paired by sex and age. These 20 subjects of the control group were volunteers who signed an informed consent form, and they all were nonsmokers, had no respiratory symptoms whatsoever, and no past or present history of lung disease. They all performed spirometry, volumetric capnography, and the 6MWT.

For the 6MWT, all patients were tested by the same technician under standardized conditions in accordance with the standards of the American Thoracic Society. ${ }^{11}$ Baseline blood pressure and heart rate were measured, and oxygen saturation $\left(\mathrm{SpO}_{2}\right)$ was determined using a finger probe pulse oximeter (Nonin WristOx 3100M (Nonin, Plymouth, MN, USA)). The pulse signal was carefully observed for at least 20 seconds, and the most frequent value on display, measured with a good pulse signal, was chosen. Saturation was measured at rest and immediately after the end of the 6-minute period, and the patients were carefully observed during the test to avoid dangerously exceeding their exercise limits. According to the American Thoracic Society guidelines, ${ }^{11} \mathrm{SpO}_{2}$ should not be used for constant monitoring during the exercise and the technician must not walk with the patient to observe $\mathrm{SpO}_{2}$.

Desaturation was calculated as the resting oxygen saturation minus oxygen saturation after the 6-minute period. For the purpose of data analysis, a cut-off value for desaturation of $4 \%$ was chosen, which means a decrease in $\mathrm{SpO}_{2}$ from baseline $>4 \%$. The $4 \%$ fall was validated in a study ${ }^{12}$ of exercise-induced hypoxemia during maximal exercise tests in athletes. Concerning the distance walked in the 6MWT, a cut-off of $400 \mathrm{~m}$ was chosen.

Pulmonary function tests were performed using a spirometer (Easy one-PC ${ }^{\circledR}$; ndd, Switzerland) and the values of forced vital capacity (FVC), forced expiratory volume in the first second $\left(\mathrm{FEV}_{1}\right)$, and $\mathrm{FEV}_{1} / \mathrm{FVC}$ ratio were analyzed. Reference values for the Brazilian population ${ }^{13}$ were used. FVC and $\mathrm{FEV}_{1}$ were expressed as a percent of the predicted value.

For the capnographic measurements, a $\mathrm{CO}_{2} \mathrm{SMOS}$ Plus 8100 Dixtal/Novametrix ${ }^{\circledR}$ (Respironics, Murrisville, PA, USA) was used. The subjects remained breathing at tidal volume for a period of 4 minutes, during which time the variables were measured and the data were stored in the computer (software Analysis Plus ${ }^{\circledR}$ ). At the end of data collection, an offline sequence of the respiratory cycles of the subjects was selected to accommodate a variation of $<15 \%$ for expiratory tidal volume and of $<5 \%$ for end-tidal concentration of $\mathrm{CO}_{2}$ $\left(\mathrm{EtCO}_{2}\right)$ tension. The respiratory cycles, those presenting phase 3 slope values of zero, were excluded; for each of the measurements a mean value was determined. 
The mean values of capnography, spirometry, and 6MWT for the three groups (NCB, BC, and controls) were determined. All subjects had their capnographic, spirometric, and variables of the 6MWT compared with the appropriate tests (Wilcoxon or Student's $t$-test); differences were considered significant with $P<0.05$.

Approval for the use of patient data was obtained from the Research Ethics Committee of the Medical School of the State University of Campinas (UNICAMP).

\section{Results}

Clinical data (age, sex, body mass index [BMI]) and functional data (spirometry, capnography, 6MWT) of subjects from the NCB group and the control group are shown in Table 1. All patients in the NCB group and the control group were nonsmokers. Concerning clinical parameters, only BMI

Table I Comparison between patients with NCB and control group

\begin{tabular}{|c|c|c|c|}
\hline & $\begin{array}{l}\text { NCB } \\
(\mathrm{N}=20)\end{array}$ & $\begin{array}{l}\text { Control group } \\
(\mathrm{N}=\mathbf{2 0})\end{array}$ & $P$ \\
\hline Age (years) & $48.3 \pm 18.4$ & $47.1 \pm 16.6$ & $0.823^{* * *}$ \\
\hline BMI $\left(\mathrm{Kg} / \mathrm{m}^{2}\right)$ & $23.1 \pm 4.7$ & $25.4 \pm 2.7$ & $0.022^{*}$ \\
\hline $\mathrm{FEV}_{1}(\%$ predicted $)$ & $56.5 \pm 18.4$ & $99.3 \pm 19.6$ & $<0.000 I^{* *}$ \\
\hline FVC (\% predicted) & $64.6 \pm 13.1$ & $97.5 \pm 18.7$ & $<0.000$ I $^{* *}$ \\
\hline $\mathrm{FEV}_{1} / \mathrm{FVC}$ & $70.4 \pm 14.6$ & $81.9 \pm 14.6$ & $0.011 *$ \\
\hline PEF (\% predicted) & $51.3 \pm 14.6$ & $58.7 \pm 36.6$ & $0.245^{*}$ \\
\hline 6MWD $(\mathrm{m})$ & $445.7 \pm 159.9$ & $538.9 \pm 90.8$ & $0.006^{*}$ \\
\hline$\Delta$ saturation (\%) & $-0.4 \pm 1.6$ & $0.9 \pm 1.1$ & $0.001 * *$ \\
\hline $\mathrm{Ve}(\mathrm{mL})$ & $502.0 \pm 150.0$ & $589.5 \pm 150.0$ & $0.120 * *$ \\
\hline $\mathrm{Te}(\mathrm{s})$ & $2.3 \pm 0.5$ & $2.8 \pm 0.5$ & $0.060^{*}$ \\
\hline $\mathrm{Ti}(\mathrm{s})$ & $1.5 \pm 0.4$ & $1.8 \pm 0.4$ & $0.027 * *$ \\
\hline Slope $2(\mathrm{mmHg} / \mathrm{L})$ & $257.7 \pm 109.3$ & $332.0 \pm 100.6$ & $0.031 * *$ \\
\hline Slope 3/Ve & $0.07 \pm 0.06$ & $0.02 \pm 0.06$ & $<0.001 *$ \\
\hline Slope $3 / \mathrm{EtCO}_{2}$ & $0.9 \pm 0.4$ & $0.3 \pm 0.1$ & $<0.000 I^{*}$ \\
\hline $\mathrm{MV}(\mathrm{L})$ & $8.0 \pm 2.1$ & $7.6 \pm 2.1$ & $0.607 * *$ \\
\hline RR (cicles/m) & $16.5 \pm 3.4$ & $|3.8 \pm 4|$. & $0.033 * *$ \\
\hline $\mathrm{Ve}(\mathrm{mL} / \mathrm{Kg})$ & $8.6 \pm 2.7$ & $8.4 \pm 2.3$ & $0.798^{* *}$ \\
\hline $\mathrm{Vd} / \mathrm{Vt}$ aw & $0.30 \pm 0.08$ & $0.26 \pm 0.06$ & $0.072^{* *}$ \\
\hline $\mathrm{EtCO}_{2}$ & $32.9 \pm 5.2$ & $35.1 \pm 4.3$ & $0.157^{* *}$ \\
\hline $\mathrm{VCO}_{2} / \mathrm{br}$ & $10.2 \pm 3.5$ & $15.5 \pm 6.8$ & $0.008^{*}$ \\
\hline $\mathrm{VCO}_{2}(\mathrm{~mL} / \mathrm{m})$ & $157.5 \pm 8.3$ & $192.6 \pm 10.6$ & $0.013^{* *}$ \\
\hline
\end{tabular}

Notes: All spirometric measurements (FVC, FEV , and PEF) correspond to the values obtained after the use of bronchodilator. *Mann-Whitney test; **Student's $t$-test; values expressed in mean $\pm S D ; P<0.05$ was considered to be a statistically significant difference.

Abbreviations: 6MWD, walked distance in the 6-minute walk test; $\Delta$ saturation, difference between baseline pulse saturation and saturation at the final of the 6-minute walk test; $\mathrm{BMI}$, body mass index; $\mathrm{EtCO}_{2}$, end-tidal $\mathrm{CO}_{2} ; \mathrm{FEV}_{1}$, forced expiratory volume in I second; FVC, forced vital capacity; MV, quantity of air inhaled expressed in terms of volume per minute; NCB, non-cystic fibrosis bronchiectasis; PEF, peak of expiratory flow; RR, respiratory rate; SD, standard deviation; Slope 3/ $\mathrm{EtCO}_{2}$, slope 3 normalized by end-tidal $\mathrm{CO}_{2}$; Slope 3/VT, slope 3 normalized by tidal volume; $\mathrm{Te}$, duration of the expiratory phase; $\mathrm{Ti}$, duration of the inspiratory phase; $\mathrm{VCO}_{2}$, the volume of $\mathrm{CO}_{2}$ produced; $\mathrm{VCO}_{2} / \mathrm{br}$, excretion of $\mathrm{CO}_{2}$ per breath; $\mathrm{Vd} / \mathrm{Vt}$ aw, deadspace volume by tidal volume ratio; $\mathrm{Ve}$, expired tidal volume. was different between the two groups, with higher values in the control group $(P=0.022)$.

As for spirometric variables, determined after the use of bronchodilator, $\mathrm{FEV}_{1}(P<0.0001)$, FVC $(P<0.0001)$ and $\mathrm{FEV}_{1} / \mathrm{FVC}$ ratio $(P=0.011)$ were worse in $\mathrm{NCB}$ patients. The NCB group had FVC less than the lower limit of the range of predicted values more often than the control group $(P<0.0001)$ (Figure 1).

The mean 6MWT distance was lower in the bronchiectasis group compared with control group $(P=0.006)$ and no significant drop in saturation happened at the end of the 6-minute walk in either group.

Regarding capnographic variables, mean expiratory tidal volume (Ve), mean expiratory volume normalized by weight in kilograms (Ve/kg), mean expiratory time (Te), mean minute volume (MV), mean airway dead space (VD/VT aw), mean peak expiratory flow (PEF), and mean $\mathrm{EtCO}_{2}$ were similar in the NCB and control groups. The mean inspiratory time was longer in the control group $(P=0.028)$; the mean total respiratory rate $(\mathrm{RR})$ was higher in patients with bronchiectasis. The mean Slp2 was lower in NCB patients $(P=0.031)$; the mean phase 3 slope normalized by the mean expiratory volume $(\mathrm{Slp} 3 / \mathrm{Ve})$ or by the $\mathrm{EtCO}_{2}$ concentration $\left(\mathrm{Slp} 3 / \mathrm{EtCO}_{2}\right)$ was greater in NCB patients $(P=0.0003$ and $P<0.0001$, respectively). The mean volume of $\mathrm{CO}_{2}$ eliminated during each breath was higher in the control group.

The comparison between the group of patients with bronchiectasis and the group of patients with severe COPD (GOLD 3 and 4) showed that bronchitic COPD patients were significantly older $(P<0.001)$, but the two groups had similar BMIs. The data of the groups are shown in Table 2.

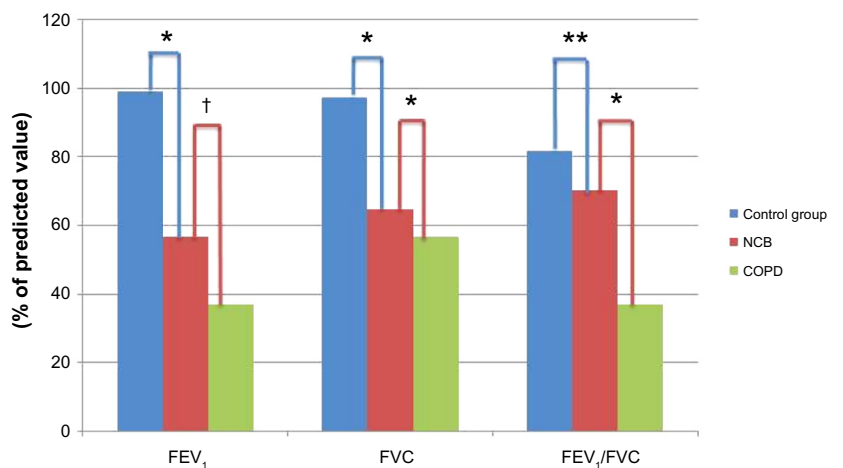

Figure I Comparison between mean values of spirometric parameters of the three groups: control, NCB, and COPD (FEV, and FVC shown as percentage predicted value).

Notes: $* P<0.0001 ; * * P=0.01 ;{ }^{\dagger} P>0.05$

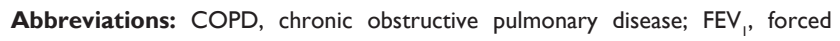
expiratory volume in the first second; FVC, forced vital capacity; NCB, non-cystic fibrosis bronchiectasis. 
As for spirometric variables, patients with bronchiectasis (NCB group) had significantly better $\mathrm{FEV}_{1}, \mathrm{FEV}_{1} / \mathrm{FVC}$, and PEF than the patients with chronic bronchitis COPD (COPD group) $(P<0.001, P<0.0001$, and $P=0.002$, respectively). Both groups had measurements of FVC below the lower limit of the expected value with high and similar frequency (90\% for the NBC group, 95\% for the COPD group) (Figure 1).

Eighty percent of bronchiectasis patients had an $\mathrm{FEV}_{1} /$ FVC ratio greater than 0.7 and $95 \%$ of the patients with chronic bronchitis had it lower than $0.7(P<0.0001)$.

In the 6MWT, mean walk distance was lower in patients with chronic bronchitis $(P=0.044)$, as well as the saturation before the test $(P<0.001)$. A fall of four or more percentage points at the end of the 6MWT was more frequent among patients with chronic bronchitis than among the subjects with bronchiectasis $(P=0.029)$, as was the finding of a walk distance shorter than $400 \mathrm{~m}(P=0.027)$.

Regarding capnographic variables, Ve, Te, Ti, MV, RR, $\mathrm{Ve} / \mathrm{kg}, \mathrm{V}_{\mathrm{D}} / \mathrm{V}_{\mathrm{T}}$ aw, and PEF were similar in COPD and NCB groups. Also no significantly different values for Slp2, $\mathrm{Slp} 3 / \mathrm{Ve}$, and $\mathrm{Slp} 3 / \mathrm{EtCO}_{2}$ were found. The $\mathrm{EtCO}_{2}, \mathrm{VCO}_{2} /$ br, and $\mathrm{VCO}_{2}$ were significantly higher in $\mathrm{COPD}$ than in NCB patients ( $P=0.024, P=0.041, P=0.006$, respectively) (Figure 2).

Table 2 Comparison between patients with NCB and COPD patients

\begin{tabular}{|c|c|c|c|}
\hline Variable & $\begin{array}{l}\text { NCB } \\
(\mathrm{N}=20)\end{array}$ & $\begin{array}{l}\text { COPD } \\
(\mathrm{N}=\mathbf{2 0})\end{array}$ & $P$-value \\
\hline Age (years) & $48.3 \pm 18.4$ & $65.7 \pm 7.4$ & $<0.001 *$ \\
\hline BMI $\left(\mathrm{Kg} / \mathrm{m}^{2}\right)$ & $23.1 \pm 4.7$ & $25.0 \pm 6.2$ & $0.278 * *$ \\
\hline FVC (\% predicted) & $64.6 \pm 13.1$ & $56.8 \pm 12.2$ & $0.059 * *$ \\
\hline $\mathrm{FEV}_{1}$ (\% predicted) & $56.5 \pm 18.4$ & $36.9 \pm 12.3$ & $<0.00 I^{* *}$ \\
\hline $\mathrm{FEV}_{1} / \mathrm{FVC}$ & $70.4 \pm 14.6$ & $50.4 \pm 10.3$ & $<0.000$ I $^{* *}$ \\
\hline PEF (\% predicted) & $51.3 \pm 19.8$ & $32.6 \pm 14.1$ & $0.002 * *$ \\
\hline $\mathrm{SpO}_{2}(\%)$ & $96.1 \pm 2.6$ & $92.3 \pm 1.8$ & $<0.000 I^{* *}$ \\
\hline 6MWD (m) & $445.7 \pm 159.9$ & $353.8 \pm 88.2$ & $0.044^{*}$ \\
\hline$\Delta$ saturation (\%) & $-0.4 \pm 1.6$ & $-2.4 \pm 1.9$ & $<0.00 I^{*}$ \\
\hline Slope 2 (mmHg/L) & $257.7 \pm 109.3$ & $235.5 \pm 93.2$ & $0.493 * *$ \\
\hline Slope 3/Ve & $0.08 \pm 0.06$ & $0.07 \pm 0.05$ & $0.749 * *$ \\
\hline Slope $3 / \mathrm{EtCO}_{2}$ & $0.93 \pm 0.46$ & $0.94 \pm 0.33$ & $0.992 * *$ \\
\hline
\end{tabular}

Notes: All spirometric measurements (FVC, FEV , and PEF) correspond to the values obtained after the use of bronchodilator. *Mann-Whitney test; **Student's $t$-test; values expressed in mean $\pm S D ; P<0.05$ was considered to be a statistically significant difference.

Abbreviations: 6MWD, walked distance in the 6-minute walk test; $\Delta$ saturation, difference between baseline pulse saturation and saturation at the final of the 6-minute walk test; BMI, body mass index; COPD, chronic obstructive pulmonary disease; $\mathrm{EtCO}_{2}$, end-tidal $\mathrm{CO}_{2} ; \mathrm{FEV}_{1}$, forced expiratory volume in I second; FVC, forced vital capacity; NCB, non-cystic fibrosis bronchiectasis; PEF, peak of expiratory flow (L/second); SD, standard deviation; Slope $3 / \mathrm{EtCO}_{2}$, slope 3 normalized by $\mathrm{EtCO}_{2}$; Slope $3 / \mathrm{Ve}$, slope 3 normalized by expired tidal volume; $\mathrm{SpO}_{2}$, oxygen saturation.

\section{Discussion}

The analysis of the results of the comparison between the group of NCB patients and the control group, regarding the spirometric variables, shows that patients were significantly different from controls and had moderate obstructive disease with reduced $\mathrm{FVC}$.

In the 6MWT, the NCB patients walked shorter distances than the controls, but the mean distance walked was greater than $400 \mathrm{~m}$, a figure accepted as within normal limits.

In the capnographic measurements, the values of Slp2 (smaller), and of Slp3/Ve and Slp3/EtCO 2 (greater), for the NCB group were significantly different from the control group. The Slp2 depicts the removal of $\mathrm{CO}_{2}$ from the alveoli, which are at the end of smaller airway paths. The branching of the bronchial tree, designed to fill the volume of the chest, allows the existence of paths of different lengths to the membrane for gas exchange; ie, to the alveoli. The more or less rapid rise in the concentration of $\mathrm{CO}_{2}$ in exhaled air at the end of the elimination of air from the anatomic dead space determines the slope of phase 2 of the volumetric capnogram and reflects the elimination of $\mathrm{CO}_{2}$ that comes from these shortest paths. Steeper slopes of phase 2 allow us to suppose that there are short branches of the bronchial tree occupying all spaces located within short distances from the central axis of the tree (the trachea). Therefore, normal individuals should have greater Slp2 than patients with lung diseases that reduce the number of these short paths. Phase 3 of the volumetric capnogram represents the elimination of $\mathrm{CO}_{2}$ from most of the alveoli and in normal individuals is almost a plateau, with a slight upward slope. The Slp3 should therefore be small. Increases in Slp3 happen in situations of heterogeneous involvement of the distal air spaces, which lead to heterogeneous distribution of the air in these regions and reduced area of contact between the $\mathrm{CO}_{2}$ that crosses the alveolar-capillary membrane and the renewed air that arrived in the previous inspiration. Larger values of Slp3/Ve and $\mathrm{Slp} 3 / \mathrm{EtCO}_{2}$ in patients suggest the existence of structural damage to the peripheral lung, which promotes this heterogeneous distribution of ventilation. ${ }^{2,3}$

The comparison between the NCB group and the group of patients with COPD GOLD 3 and 4 revealed that individuals with COPD had much worse spirometric values, walked less than $400 \mathrm{~m}$, and desaturated four or more percentage points with a significantly higher frequency than patients with bronchiectasis (Table 2).

Spirometry and the 6MWT were able to demonstrate that individuals with COPD had worse disease than patients with bronchiectasis. However, the capnographic variables Slp2, $\mathrm{Slp} 3 / \mathrm{Ve}$, and $\mathrm{Slp} 3 / \mathrm{EtCO}_{2}$ were similar in both groups. 


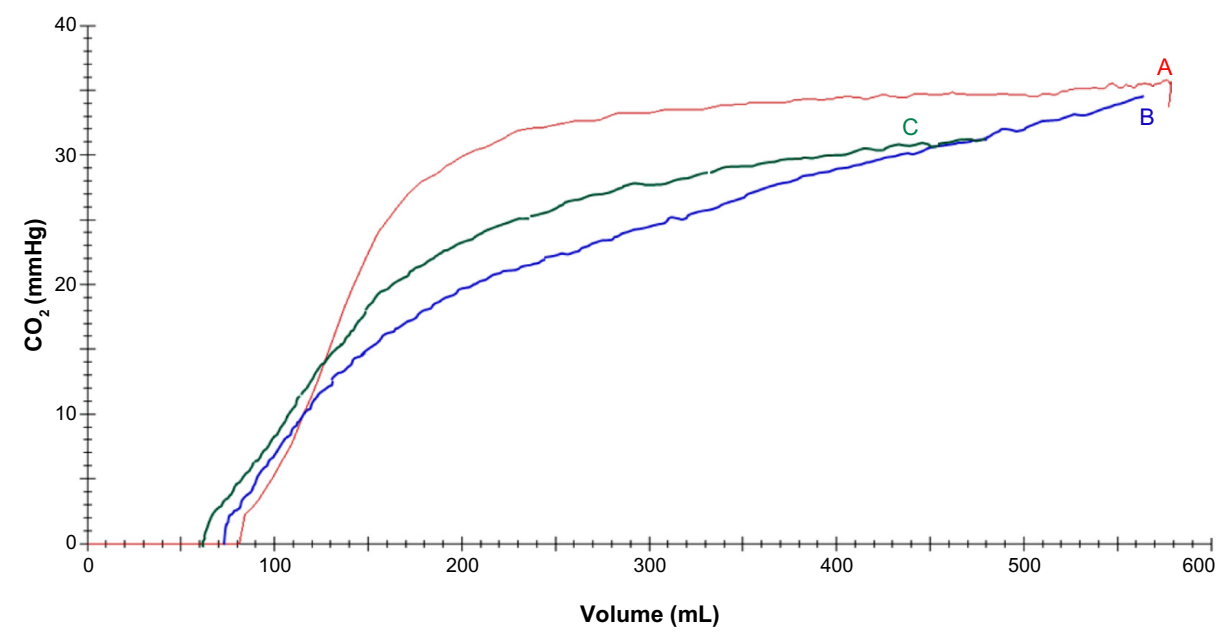

Figure 2 Curves of volumetric capnography of control (A), bronchiectasis (B), and COPD (C) groups (representative curves).

Notes: $(\mathbf{A}) \mathrm{EtCO}_{2}=35.1 \mathrm{mmHg} ; \mathrm{Ve}=590 \mathrm{~mL}$; Slope $3=11.17 \mathrm{mmHg} / \mathrm{L}$. (B): $\mathrm{EtCO}=32.9 \mathrm{mmHg} ; \mathrm{Ve}=502 \mathrm{~mL} ; \mathrm{Slope} 3=32.05 \mathrm{mmHg} / \mathrm{L}$. (C) EtCO $=36.8 \mathrm{mmHg} ; \mathrm{Ve}=589 \mathrm{~mL}$; Slope $3=34.10 \mathrm{mmHg} / \mathrm{L}$.

Abbreviations: COPD, chronic obstructive pulmonary disease; $\mathrm{EtCO}_{2}$, end-tidal $\mathrm{CO}_{2}$.

These findings may show that capnography is not able to differentiate between the different types of structural disease shown by these groups, and is not sensitive to the worse clinical condition of the COPD patients.

It is very difficult to monitor the progression of structural abnormalities in both diseases (NCB and COPD) and this was not a longitudinal study, so making statements about progression is not appropriate.

Cosio et al, ${ }^{14}$ in a fundamental study published in 1978 , demonstrated that structural changes in small airways of susceptible smokers with smoking histories greater than 35 packyears could be reflected in the nitrogen single-breath washout test. Increasing pathology scores (that included evaluation of inflammatory cell infiltrate, squamous cell metaplasia of the airway epithelium, and airway wall fibrosis) of the small airways ( $<2 \mathrm{~mm}$ internal diameter) were accompanied by increasing ventilation heterogeneity as measured from the $\mathrm{N}_{2}$ phase 3 slope of the single-breath washout test. This test of unevenness of ventilation could detect structural changes in the small airways of smokers long before spirometry could. But this measurement produced deceiving results in predicting decline of $\mathrm{FEV}_{1}{ }_{1}^{15,16}$ and these data agree with the findings in this study.

The pattern of decreasing or increasing gas concentrations during the multiple-breath washout tests has the potential to anatomically locate the affected small airways in acinar and conductive lung zones through increased phase 3 slope indices $\mathrm{S}_{\text {acin }}$ (acinar lung zone) and $\mathrm{S}_{\text {cond }}$ (conductive lung zone). ${ }^{17}$ These calculations allowed the determination of the relative contribution of conductive and acinar airspaces in diseases such as asthma,${ }^{18}$ cystic fibrosis,${ }^{19}$ and $\mathrm{COPD},{ }^{20}$ and in conditions such as aging. ${ }^{21}$
In volumetric capnography, $\mathrm{CO}_{2}$ concentration is analyzed during multiple breaths, on average more than 50 breaths, but the pattern of elimination for an individual shows small variations from breath to breath due to the steady supply of $\mathrm{CO}_{2}$ to the lungs. This aspect of volumetric capnography probably makes it less informative than the classical, sophisticated, and more expensive multiple-breath washout tests.

Nevertheless, perhaps the natural histories of both diseases evaluated here have differences that justify the findings of the present study. Chronic bronchitis associated with smoking is caused by the toxic action of many substances produced by burning tobacco that are repeatedly inhaled by the smokers. Generally all smokers have a productive cough, at least in the morning soon after waking up; however, not all smokers will have airflow obstruction on spirometry. Those individuals who develop obstructive disease are characterized as COPD patients. The airflow obstruction in COPD happens when there are structural changes in small airways and/or alveoli. ${ }^{22,23}$ Apparently, all smokers have proximal airway injury, but only a variable percentage also have peripheral structural lesions. ${ }^{10}$

Patients with severe COPD thus have proximal and distal changes in the airways that are sequential or almost simultaneous, but may certainly occur earlier in the proximal airways. The reason why only a few smokers develop COPD is still unknown. However, it can be speculated that the structure of the bronchial tree may be one of many factors that favor the onset of the disease. Simplification of the bronchial tree branching, either congenital or acquired in the postnatal period as a result of an infection in childhood, may facilitate the action of toxic substances from cigarettes, allowing them to reach further down the airways. 
Bronchiectasis appears to have a different natural history. The initial lesion in bronchiectasis most likely occurs in the small airways (bronchioles of less than $2 \mathrm{~mm}$ in diameter). Evidence supporting this hypothesis is available for cystic fibrosis, a disease that progresses with extensive dilation of central bronchi. Before bronchiectasis appears, clear signs of small airways disease are detectable by lung function evaluation and imaging studies such as a computed tomography (CT) scan of the chest. ${ }^{24}$ In cystic fibrosis, the mucociliary transport is severely compromised by the reduced amount of water in the periciliary liquid. ${ }^{25-27}$

In ciliary dyskinesia, a disease that also causes dilation of the central bronchi, CT signs of bronchiolitis, especially the pattern described as "tree-in-bud" on high-resolution CT scans of the chest, are very often found in areas of the lung without dilated central bronchi. The loss of cilia beating in subjects with ciliary dyskinesia decreases the efficiency of mucociliary transport, a situation that seems to be common to many of the diseases that cause bronchiolitis/bronchiectasis. ${ }^{26}$

Again, the structure explains the importance of lung mucociliary transport for the removal of secretions in the small airways. Bronchial branching does significantly increase the cross-sectional area of the distal airspaces. The movement of gases by pressure (convection), which generates airflow, happens to some extent in the airways. The increased cross-sectional area in the distal air spaces causes airflow to drop dramatically. Failure to maintain adequate flow interferes with the ability to generate effective cough. Without cough, elimination of respiratory secretions, that trap biological and non-biological particles and many diluted or cross-linked toxic substances, is entirely dependent on mucociliary transport. ${ }^{28}$

In idiopathic bronchiectasis, although the causative mechanism of mucociliary transport impairment is unknown, the presence of tomographic signs of bronchiolitis in lung regions where dilatation of the central bronchi are not yet detected has been demonstrated; other areas show both bronchiolitis and bronchiectasis. ${ }^{29}$

In $1950, \operatorname{Reid}^{30}$ published a cornerstone study on the pathology of extensive bronchiectasis, whose conclusions cleared many intriguing aspects of this condition. One of the most important findings was the reduction of bronchial subdivisions between the hilum and the periphery of the lung, especially in the saccular type of bronchiectasis. The missing bronchi, whenever their remnants could be identified, were obliterated by fibrous tissue and all the generations of bronchi and small airways that should arise from them had completely disappeared.
The combination of these findings with the visualization of signs of small airway disease on high-resolution CT scans of the chest (air trapping and/or tree-in-bud) allow us to hypothesize that in diffuse bronchiectasis the most important and probably most initial lesions occur in the small airways of less than $2 \mathrm{~mm}$ in diameter because their dependence on mucociliary clearance and other airway defense mechanisms is much greater than in central airways. The accelerated and heterogeneous loss of small airways, through inflammation and fibrous obliteration, may lead to a highly variable distribution of gases in the distal air spaces and a reduction in the area of contact between the gas in the alveoli and the new gas that arrives at each inspiration.

These lesions may happen earlier and be more intense in conditions that cause diffuse bronchiectasis than in COPD patients and the slope of phase 3 in the volumetric capnogram and other single-breath washout curves could be specially suited to detect them.

Dutrieue et al, ${ }^{31}$ in their work published in 2000, demonstrated that the phase 3 slope, which is generally referred to as a marker of small airway alterations, showed great sensitivity to intra-acinar asymmetry, which can be a property of the acinus related to the asymmetric branching pattern of the airways or may be produced or aggravated by disease conditions that affect distal airspaces.

The lung clearance index (LCI), derived from the concentration curves obtained during a multiple-breath washout and used to quantify the inefficiency in gas mixing in the lungs, has been considered a valuable tool for early detection of lung structure alterations in children with cystic fibrosis. ${ }^{1,32,33}$

But Verbanck et al, ${ }^{34}$ in their work published in 2012, concluded that although LCI can potentially be affected by a structural change in the small airways, it can be modified likewise by structural changes in more proximal airways. In addition, a simple increase in anatomical dead space (common in bronchiectasis patients) leads to an LCI increase. Hence, LCI is not a small airway test in the sense that any observed change in LCI cannot be readily interpreted as the unequivocal reflection of a structural alteration of the small airways.

The role of normalized phase 3 slope may be worth exploring as a more sensitive index of small airway disease, even though it may not be equally sensitive in discriminating the severity of the alterations. Volumetric capnography may be an easier and less expensive way of measuring phase 3 slopes in a significant number of chronic lung diseases. 


\section{Disclosure}

The authors report no conflicts of interest in this work.

\section{References}

1. Robinson PD, Goldman MD, Gustafsson PM. Inert gas washout: theoretical background and clinical utility in respiratory disease. Respiration. 2009;78(3):339-355.

2. Ribeiro MÂ, Silva MT, Ribeiro JD, et al. Volumetric capnography as a tool to detect early peripheric lung obstruction in cystic fibrosis patients. J Pediatr (Rio J). 2012;88(6):509-517.

3. Almeida CC, Almeida-Júnior AA, Ribeiro MA, Nolasco-Silva MT, Ribeiro JD. Volumetric capnography to detect ventilation inhomogeneity in children and adolescents with controlled persistent asthma. J Pediatr (Rio J). 2011;87(2):163-168.

4. Veronez L, Moreira MM, Soares ST, et al. Volumetric capnography for the evaluation of pulmonary disease in adult patients with cystic fibrosis and noncystic fibrosis bronchiectasis. Lung. 2010;188(3):263-268.

5. Moreira MM, Terzi RG, Carvalho CH, de Oliveira Neto AF, Pereira MC, Paschoal IA. Alveolar dead space and capnographic variables before and after thrombolysis in patients with acute pulmonary embolism. Vasc Health Risk Manag. 2009;5(1):9-12.

6. Moreira MM, Terzi RG, Paschoal IA, Martins LC, Oliveira EP, Falcão AL. Thrombolysis in massive pulmonary embolism based on the volumetric capnography. Arq Bras Cardiol. 2010;95(4):e97-e99.

7. Pereira DJ, Moreira MM, Paschoal IA, Martins LC, Metze K, Moreno Junior H. Near-fatal pulmonary embolism in an experimental model: hemodynamic, gasometric and capnographic variables. Rev Bras Cir Cardiovasc. 2011;26(3):462-468.

8. Schwardt JD, Gobran SR, Neufeld GR, Aukburg SJ, Scherer PW. Sensitivity of $\mathrm{CO} 2$ washout to changes in acinar structure in a singlepath model of lung airways. Ann Biomed Eng. 1991;19(6):679-697.

9. Schreiner MS, Leksell LG, Gobran SR, Hoffman EA, Scherer PW, Neufeld GR. Microemboli reduce phase III slopes of $\mathrm{CO}_{2}$ and invert phase III slopes of infused SF6. Respir Physiol. 1993;91(2-3): $137-154$.

10. Vestbo J, Hurd SS, Agustí AG, et al. Global strategy for the diagnosis, management, and prevention of chronic obstructive pulmonary disease: GOLD executive summary. Am J Respir Crit Care Med. 2013;187(4): 347-365.

11. ATS Committee on Proficiency Standards for Clinical Pulmonary Function Laboratories. ATS statement: guidelines for the six-minute walk test. Am J Respir Crit Care Med. 2002;166(1):111-117.

12. Préfaut C, Durand F, Mucci P, Caillaud C. Exercise-induced arterial hypoxaemia in athletes: a review. Sports Med. 2000;30(1):47-61.

13. Pereira CA, Sato T, Rodrigues SC. New reference values for forced spirometry in white adults in Brazil. J Bras Pneumol. 2007;33(4): 397-406.

14. Cosio M, Ghezzo H, Hogg JC, et al. The relations between structural changes in small airways and pulmonary-function tests. $N$ Engl J Med. 1978;298(23):1277-1281.

15. Stănescu DC, Rodenstein DO, Hoeven C, Robert A. "Sensitive tests" are poor predictors of the decline in forced expiratory volume in one second in middle-aged smokers. Am Rev Respir Dis. 1987;135(3):585-590.
16. Buist AS, Vollmer WM, Johnson LR, McCamant LE. Does the singlebreath N2 test identify the smoker who will develop chronic airflow limitation? Am Rev Respir Dis. 1988;137(2):293-301.

17. Verbanck S, Schuermans D, Meysman M, Paiva M, Vincken W. Noninvasive assessment of airway alterations in smokers: the small airways revisited. Am J Respir Crit Care Med. 2004;170(4):414-419.

18. Verbanck S, Schuermans D, Paiva M, Vincken W. Nonreversible conductive airway ventilation heterogeneity in mild asthma. J Appl Physiol (1985). 2003;94(4):1380-1386.

19. Verbanck S, Paiva M, Schuermans D, Malfroot A, Vincken W, Vanderhelst E. Acinar and conductive ventilation heterogeneity in severe CF lung disease: back to the model. Respir Physiol Neurobiol. 2013;188(2):124-132.

20. Verbanck S, Schuermans D, Van Muylem A, et al. Conductive and acinar lung-zone contributions to ventilation inhomogeneity in COPD. Am J Respir Crit Care Med. 1998;157(5 Pt 1):1573-1577.

21. Verbanck S, Thompson BR, Schuermans D, et al. Ventilation heterogeneity in the acinar and conductive zones of the normal ageing lung. Thorax. 2012;67(9):789-795.

22. Hogg JC, Timens W. The pathology of chronic obstructive pulmonary disease. Annu Rev Pathol. 2009;4:435-459.

23. McDonough JE, Yuan R, Suzuki M, et al. Small-airway obstruction and emphysema in chronic obstructive pulmonary disease. $N$ Engl J Med. 2011;365(17):1567-1575.

24. Tiddens HA, Donaldson SH, Rosenfeld M, Paré PD. Cystic fibrosis lung disease starts in the small airways: can we treat it more effectively? Pediatr Pulmonol. 2010;45(2):107-117.

25. Matsui H, Grubb BR, Tarran R, et al. Evidence for periciliary liquid layer depletion, not abnormal ion composition, in the pathogenesis of cystic fibrosis airways disease. Cell. 1998;95(7):1005-1015.

26. Boucher RC. Relationship of airway epithelial ion transport to chronic bronchitis. Proc Am Thorac Soc. 2004;1(1):66-70.

27. Randell SH, Boucher RC; University of North Carolina Virtual Lung Group. Effective mucus clearance is essential for respiratory health. Am J Respir Cell Mol Biol. 2006;35(1):20-28.

28. Svartengren K, Philipson K, Svartengren M, Nerbrink O, Camner P. Clearance in smaller airways of inhaled 6-microm particles in subjects with immotile-cilia syndrome. Exp Lung Res. 1995;21(5):667-682.

29. Kang EY, Miller RR, Müller NL. Bronchiectasis: comparison of preoperative thin-section $\mathrm{CT}$ and pathologic findings in resected specimens. Radiology. 1995;195(3):649-654.

30. Reid LM. Reduction in bronchial subdivision in bronchiectasis. Thorax. 1950;5(3):233-247.

31. Dutrieue B, Vanholsbeeck F, Verbanck S, Paiva M. A human acinar structure for simulation of realistic alveolar plateau slopes. $J$ Appl Physiol (1985). 2000;89(5):1859-1867.

32. Gustafsson PM, De Jong PA, Tiddens HA, Lindblad A. Multiple-breath inert gas washout and spirometry versus structural lung disease in cystic fibrosis. Thorax. 2008;63(2):129-134.

33. Horsley A. Lung clearance index in the assessment of airways disease. Respir Med. 2009;103(6):793-799.

34. Verbanck S, Paiva M, Schuermans D, Hanon S, Vincken W, Van Muylem A. Relationships between the lung clearance index and conductive and acinar ventilation heterogeneity. J Appl Physiol (1985). 2012;112(5):782-790.

International Journal of COPD

\section{Publish your work in this journal}

The International Journal of COPD is an international, peer-reviewed journal of therapeutics and pharmacology focusing on concise rapid reporting of clinical studies and reviews in COPD. Special focus is given to the pathophysiological processes underlying the disease, intervention programs, patient focused education, and self management protocols.

\section{Dovepress}

This journal is indexed on PubMed Central, MedLine and CAS. The manuscript management system is completely online and includes a very quick and fair peer-review system, which is all easy to use. Visit http://www.dovepress.com/testimonials.php to read real quotes from published authors.

Submit your manuscript here: http://www.dovepress.com/international-journal-of-copd-journal 